\title{
The Effect of Mobile Digital Content Applications Based on Gamification in the Development of Psychological Well-Being
}

\author{
https://doi.org/10.3991/ijim.v13i08.10725 \\ Waleed Salim Alhalafawy \\ King Abdulaziz University, Jeddah, Saudi Arabia Kingdom \\ Ain shams university, Cairo, Egypt \\ Marwa Zaki Tawfiq Zaki $\left({ }^{凶}\right)$ \\ Ain Shams University, Cairo, Egypt \\ dr.marwa.zaki@sedu.asu.edu.eg
}

\begin{abstract}
The aim of this research is to design a proposed model for Mobile Digital Content Applications Based on Gamification and measure its effectiveness in the development of psychological well-being among the graduate students of King Abdulaziz University who are challenged with issues related to the nature of postgraduate studies, which may affect their levels of psychological well-being. Research sample consisted of (62) students, partdicularly those who are students of the postgraduate programs at King Abdulaziz University. The study has applied the semi-experimental approach that is based on two group design. The experimental group used an application version called "My Academic Advisor", which was developed according to the proposed model, while the control group used a version that did not include any methods or tools for gamification. A measure of psychological well-being was built through the mobile digital content applications. The measure in its final version consisted of 6 themes that included (36) indicators of psychological well-being; 6 indicators for each theme. The results of the application showed the effectiveness of the proposed model of the gamification in the development of psychological wellbeing among the experimental group students compared to the students of the control group.
\end{abstract}

Keywords - Gamification; Mobile Digital Content Applications (MDCA);

Psychological Well-Being (PWB).

\section{$1 \quad$ Introduction}

Gamification is a trend in research that recently has become popular in educational. It refers to applying attributes and elements of games in educational contexts that are not play-based, that is, to bring fun and motivation to the educational environments, and to turn monotony and stereotyping learning events into an enjoyment experience $[1,2]$ Gamification in educational environment means raising challenges within the 
educational context. There are tasks that must be carried out by the learner who is given points, badges and passes through different levels depending on the way he/she performs these tasks. Moreover, learners or users are classified according to their achievement rates $[3,4]$.

Gamification is primarily based on external stimuli which sometimes has a negative impact on self-motivation. People who perform activities due to external incentives, once removed, they become less willing to perform learning tasks and activities [5-7]. However, some research studies that aimed at analyzing performances and tasks implementation that are stimulated by external incentives as compared to those not stimulated by any incentives have shown that the effectiveness of the performance and task implementation is in favor of the group that was supported by incentives, as indicated by study [8] that examined 12 different studies which aimed at running (25) comparisons; these comparisons included incentive assisted performance vs performances that did not receive any incentive at all. The results have shown an effect degree of (0.6) in favor of groups that obtained additional external incentives, which means that it is difficult to develop an educational system without considering the motivational system involved in this system.

[9], With regards to MDCA that has been developed to deliver content for learners, McLoughlin believes that these applications are very important because they support dynamic technologies that provide the learner with an opportunity of education that has greater control, self-autonomy, and make the learner more connected to learning events because most of them are adaptive to their characteristics and meet the learner's needs. Digital content applications also make the learner more interactive because the content is formulated in accordance with the learner's perspective and the way he/she processes information. Therefore, it is important to study the structure of digital incentives through applications of digital mobile content and determine the mechanism of implementing and managing them in a way that optimizes the use of these applications, especially under the confirmation of a variety of studies that the use of methods and tools for mixing in digital environments needs further studies $[10,11]$.

Postgraduate students face challenging situations that make them in need of enhancing a feeling of well-being, and thus avoid any negative feelings. This invites researchers to search for reliable tools that could enhance the psychological wellbeing. However, some studies have shown an existence of a positive relationship between the mobile digital content media and applications and the psychological wellbeing; this means that it is possible to rely on the mobile applications gamification incentives for enhancing psychological well-being $[12,13]$. In fact, the current research is trying to investigate this issue by studying the relationship between the gamification of the mobile digital content and psychological well-being among postgraduate students.

The current research thus tries to answer the following questions:

- (RQ1) What are the themes and indicators of Psychological Well-being that could be obtained through Mobile Digital Content Applications?

- (RQ2) What is the proposed model of the mobile digital content gamification for the development of PWB among postgraduate students? 
- (RQ3) How effectiveness is the proposed model of the mobile digital content gamification for the development of PWB among postgraduate students?

\subsection{The current search also tries to validate the following hypothesis:}

(H1) There is no statistical difference at the level 0.05 between the average scores of the experimental group; the one who uses a mobile application based on gamification, and the average scores of the experimental group; the one who uses a mobile application without any methods of gamification in the post measurement of PWB through mobile digital content application, due to gamification tools influence.

\section{$2 \quad$ Literature Review}

\subsection{Gamification}

Generally, gamification is a term that is closely related to Games, and not Play. This is because playing offers more freedom and a bit of restraints, unlike games that mean constraints, challenges, competition, and goals to be pursued and realized [2, 14]. Gamification is known to be the use of game design elements in a non-game contexts not depending on playing" [15], also known as Using game-based mechanics, aesthetics and game thinking to engage people, motivate action, promote learning, and solve problems [16]. In a more in-depth look at the concept of gamification, four terms that are relevant to the concept of gamification can be emphasized [15, 17]:

- Game as a Term: Refers It refers to a presence of the following components: a goal to be achieved, rules to determine how to reach the goal, feedback system that provides information on the level of progress towards the goal, and finally voluntary participation.

- Element as a Term: It helps distinguish between the concept of gamification and serious games which are used as whole games but for non-recreational purposes. Gamification refers to the explicit use of certain elements: points, badges, leaderboards, progress bars that are used in non-gaming contexts.

- Design as a Term: It means the use of Game Design instead of game-based technologies. This is because gamification invests in the design elements and not the technologies and programming that are used in developing digital games.

- Non-gaming Contexts as a Term: The field of applying gamification is very broad and not limited with restrictions, and as mentioned before, gamification is used in non-gaming contexts.

\subsection{Mobile digital content applications (MDCA)}

Anderson believes that MDCA are e-services that connect a group of individuals who share common characteristics and interests in a frame of human relationships. Anderson sees mobile digital content applications as "a more interactive, participatory 
and social development of the forms and tools used across networks"[18]. This happens through a growing set of tools that learners use to gather information and interact in appropriate ways [19-21]. Here MDCA succeed to make a big move in web technologies rendering them as more creative and attractive, [22], through a philosophy to maximize collective intelligence among a group of users which added value to every user participating with a dynamic information [23]. Mobile social applications are tools that provide unique opportunities to socially exchange all kinds of information and multimedia through synchronous and asynchronous communications that encourage interaction and sharing of different knowledge production [24, 25]. This means that MDCA are comprehensive services in which people interact usin their mobile devices, and however allows learner to share activities and interests, make friends, and look for interests and activities adopted by other learners.

When talking about the characteristics of MDCA, it can be emphasized that it is not a standard or technology per se, but a framework for delivering shared applications via new user interfaces $[22,26,27]$. The MDCA are based on a basic philosophy which says that unique content is more important than the program, because unique content is able to attract learners and provide a variety of creative and inventive opportunities, as well as keeping content as digital objects instead of pages (as understood previously) that are easy to exchange and interact [24]. Digital content applications are based on the concepts of interaction between learners that facilitate thoughtful and critical discussion in order to acquire basic knowledge; digital content applications are not simply an application to achieve a goal but rather a tool for shaping knowledge within a framework of an ongoing process of construction in which the learner is mainly involved [10]. As a result, digital content applications have changed its role from the transmission, availability and distribution of learners' educational materials and use to the idea of participating in the production of these materials, so that digital content applications become educational sources and portals rather than being objects of specific categories [28-31].

\subsection{Psychological well-beings (PWB):}

PWB can be defined as a set of behavioral indicators that generally display high levels of individual satisfaction, and can be identified with reference to six main factors as follows [32-35]:

- Autonomy: Refers to an individual's autonomy and his ability to make decisions, resist social pressures, and control personal behavior during interaction with others.

- Environmental Mastery: Refers to the ability of an individual to organize conditions and control varied activities, benefit effectively from surrounding conditions, and to provide suitable environment and personal flexibility.

- Personal Growth: Refers to the individual's ability to develop his abilities, increase his effectiveness and his personal competence in different aspects, and enhance a sense of optimism. 
- Positive Relations with other: refers to the individual's ability to form friendships and social relationships with others on the basis of friendliness, empathy, mutual trust, understanding, influence, friendship, and the willingness to give and take.

- Purpose Life: refers to the ability of an individual to define his goals in life objectively, and to have a clear goal and vision that direct his actions and behaviors, together with perseverance and insistence in order to achieve his goals.

- Self-Acceptance: refers to the ability of self-realization, positive attitudes towards one's personality and past life, and acceptance of various manifestations of the self, including positive and negative manifestations.

There is a clear relationship between gamification and PWB, where the systems give the user an independence of decision-making and freedom of choice, which is one of the basic components of PWB. Gamification helps the learner to control the implementation of activities, tasks of learning, and personal flexibility, which is reflected on the environmental capacity of the learner. Gamification considers the development of gradual levels of challenges; therefore it contributes to the development of the learner and his sense of optimism, which leads to the process of personal development, and through the joint-working groups provided through the gamification, the learner build positive relationships with others which contributes positively to the improvement of PWB. Gamification also depends on specific clear set of goals that every learner seeks to achieve through various stages, which makes the learner's life purposeful. In addition, gamification and the tasks it included, through which the learner moves using self-supported external motives, make the learner satisfied with himself and all its reflective manifestations [36-38].

\subsection{Theoretical framework}

Among digital content applications, gamification usage is supported by the SelfDetermination Theory (SDT) indicating that the learner's move toward tasks execution is driven by a set of intrinsic motivations that do not work mechanically because they require appropriate support and feedback by the environment, which is noticed through the incentives provided by the gamification system [4, 39-41].

In the learning environment, gamification usage has a correlation with the Motivation Theory (MT) definitely in the part related to extrinsic motivation, which can compensate the difference between internal incentives and the learner's actual level. It is possible that learner may have an internal desire to be high achiever in learning but may fail due to his weak scientific and cognitive abilities; therefore the external incentives have a significant role in motivating the learner to reach the desired level [42].

The basic psychological Needs Theory (BPNT) refers to the existence of a set of factors that make any activity fun and motivational to intrinsic motives, these factors are: Autonomy, Competence, and Relatedness as provided by gamification systems that stimulate independence by giving the learner a sense of willing and freedom when it comes to the implementation of tasks, It stimulates competence by giving the learner a sense of effectiveness in the accomplishment of tasks and influencing the 
environment in which they are present. Finally, they encourage the competence generated by the learner's social relationships with his peers within the learning environment and the involvement he felt in his capacity as a member of the groups formed during the task's implementation [10-12]

Flow Theory (FT) is one of the theories that supports gamification usage, although it is highly concerned with internal motives as a necessity for the state of flow; however, the incentives provided through the gamification system to push flow processes leads to a greater sense of well-being, and encourage continuity, through which learner know that he is right, which help him keep in line with the flow processes to reach the desired goal $[43,44]$.

The design of the proposed application is based on these theories so that the application work on supporting learners with incentives that meet their basic needs and compensate for the difference between their internal incentives and the desired level. In addition, it guarantees having the learners present in a continuous flow of learning through digital content applications.

\section{Methodology}

\subsection{Design}

The two group-experimental designs are used by the research team. The first group used my "academic advisor" application developed by the research team, which does not include any use of the gamification methods, while the second group is the experimental one used the application developed in line with the methods of gamification. Table (1) illustrates the experimental design of the research.

Table 1. Research experimental design

\begin{tabular}{|l|l|l|}
\hline \multicolumn{1}{|c|}{ Research both groups } & \multicolumn{1}{|c|}{ Independent variable } & \multicolumn{1}{c|}{ Dependent variables } \\
\hline Experimental group (1) & $\begin{array}{l}\text { Applying "My academic advisor" } \\
\text { application without gamification }\end{array}$ & $\begin{array}{l}\text { Psychological Well-Bing } \\
\text { through mobile digital content } \\
\text { application }\end{array}$ \\
\hline Experimental group (2) & $\begin{array}{l}\text { Applying a gamification-based } \\
\text { application of "My academic advisor" }\end{array}$ & aplen \\
\hline
\end{tabular}

The independent variables, as shown in the previous table, were based on the applications of a gamification-based digital content. The dependent variables were based on the PWB through the digital content applications.

\subsection{Sample}

The study sample consisted of (62) students out of (91) students who are studying a course named "Learning Technologies and Resources", at the General Diploma Program of Education, King Abdul-Aziz University, in the academic year 2016/2017. The sample was assigned through two stages. In the first stage, the sample individuals were chosen intentionally as per two criteria: the first was a technical criterion in 
terms of possession of suitable mobile phones by the sample individuals, in addition to using some social applications available through these phones. The second criterion was related to the consent of the sample individuals to join the research experiment, while in the second stage, sample individuals were distributed randomly with (31) students in each group.

\subsection{Measures}

In the current research, PWB is linked to indicators of well-being that happen as a result of learning through certain applications of digital mobile content. However, to prepare the scale of PWB through the applications of mobile digital content, more than one scale of PWB, including (Ryff's scale of psychological well-being, 1989), and the Psychometric Well-being Scale were developed [35]. In accordance with the nature of well-being themes as found in the previous scales, in addition to the nature of learning through MDCA and the nature of postgraduate students in the current research, the scale of PWB was developed through MDCA. The scale includes six themes:(1) self-independence (2) environmental enabling (3) personal development, (4) positive relationships, (5) purposeful life, (6) self-acceptance. The measure contains all in all (36) individuals, distributed on the six measure themes by (6) items for each theme: (3) positive, and (3) negative. The scale was presented to a group of arbitrators to verify its validity and relevance to the postgraduate students (education field). Students were asked to evaluate each item with reference to the five-scale evaluation (strongly agree, agree, neutral, disagree, strongly disagree), and degrees from 1 to 5 respectively are given in the case of positive expressions and vice versa in the case of negative expressions (items are coded based on a 5-point Likert type scale (from $1=$ strongly disagree to $5=$ strongly agree). The measure stability is ensured before application, where Cronbach's $\alpha(=0.769)$.

\subsection{Procedures}

The procedures of this research study have been implemented as compatible with the stages of the specified educational design through five main stages as follow:

Analysis stage: The educational tasks, in this stage, to be executed through the proposed model, where the current research focused on the educational content tasks and activities within a course named "educational Techniques and Learning Resources" for general diploma students (education), where (8) educational tasks related to the research and theoretical study on the educational technology innovations are determined. Nevertheless, the learner's characteristics related to using the mobile technology were analyzed. A result indicates $(76.6 \%)$ of the sample individuals own android-based mobile phones, and (93\%) of students use the mobile phone to access the internet. $(88.6 \%)$ of Students use mobile social applications, both public and private. And through applying the scale of PWB through applications of mobile digital content, the researcher showed a significant decrease in the PWB indicators in the research sample. 
Design stage: Through this stage, the proposed model is designed to use gamification in MDCA, according to the following:

Designing an Educational Objective: The educational objectives, under discussion, were related to the curriculum of educational techniques and learning resources, especially the Unit of Educational Technology Innovations. Accordingly, a list of educational objectives was established which included (18) objectives.

Designing Tasks: 8 step-by-step tasks have been designed, the first level includes two tasks for the analysis of the technical innovation characteristics and for the collection of information in multimedia model; the second level includes (3) tasks that contained recorded videos about innovations, preparing technical projects, and developing innovation visual channels.

Designing Mechanisms: An illustration has been made to each of the following: the nature of the challenges in each task, the additional opportunities that each student can receive as a result of his communication with the teacher about the tasks, the mechanisms of positive competition, how to cooperate, the timing of the feedback. It is essential to determine a list of rewards that each person can obtain, the status of every person according to the number of points and badges he collected, the announcement of the final winners according to the leaderboards, and how every student expresses himself and achievements.

Designing Gamification Tools: It has relied on (3) tools, presented as follows:

- Points: The numbers of points are assigned in each task, with total of (100) points, in accordance with table (2).

- Badges: (5) Badges were designed as follows: one for a student collaborating with his colleagues; a full grade-badge that is awarded to a student who obtains full grade in one level; the level champion badge that is given to the student who completes the level and receives all points and gets into the pride of place in terms of time; the task accomplishment badge which is given to student who completes each task separately; and distinctive badge that is provided to the person who achieves $(90 \%)$ of the total points.

- Leaderboards: They are designed to identify the order of the students according to the number of points and badges obtained by every student, as per the performance of the various tasks across the three levels identified.

Table 2. Tasks points in accordance with the graduated levels

\begin{tabular}{|c|c|c|c|c|c|}
\hline \multicolumn{2}{|c|}{ First level tasks } & \multicolumn{2}{c|}{ Second level tasks } & \multicolumn{2}{c|}{ Third level tasks } \\
\hline Number of tasks & Task points & Number of tasks & Task points & Number of tasks & Task points \\
\hline 2 & 5 & 3 & 10 & 3 & 20 \\
\hline \multicolumn{2}{|r|}{ Total of 10 points } & \multicolumn{2}{|c|}{ Total of 20 points } & \multicolumn{2}{c|}{ Total of 60 points } \\
\hline
\end{tabular}

Digital content application design "academic advisor": The proposed application includes (3) basic components:

1. Guidance tools (including 4 tools): Study Programs, Your Guidance Services, Set an Appointment, and Send an Inquiry 
2. Content tools via social media channels (including 4) tools: YouTube, Twitter, Blogger, and Instagram

3. (gamification tools “3”): Rewards, Tasks, My Rewards, News. The application tools can be displayed as follows:

- Study Programs: Through which the student learns all the basic information about graduate programs (general information about the program, program vision, program message, program objectives, program outputs, study plan, course descriptions, and program admission).

- Your Guidance Services: under which the student recognizes all guidance services that can be obtained through the application.

- Set an appointment: Through this tool, every student asks an appointment with teaching board member charged with the academic guidance.

- Send an Inquiry: every student has any query regarding the content, sends a direct inquiry to the academic advisor.

- Content (social media): digital content, through this tool, is accessed using social media applications and four main channels are identified for content delivery, including the YouTube video application, Twitter), the application of Blogger, and (Instagram).

- Rewards Regulations: Through this Regulation, the student can identify the regulations governing the complaints, the tasks required and the mechanism to obtain rewards for each task.

- My Rewards: Each student can recognize the rewards he has received as a result of his / her performance. The rewards are set in 3 types: points, badges, and leaderboards.

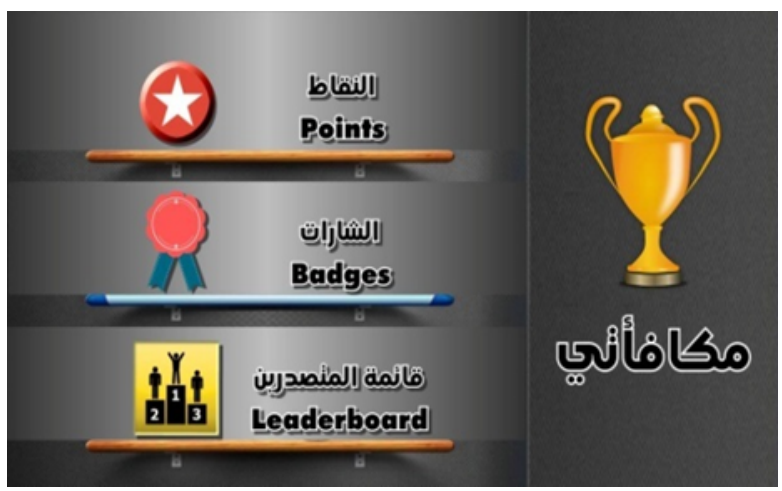

Fig. 1. Reward page with the proposed application

- News: you will be able, through this tool, to identify the latest news about the program, all news, and information about the winners of the various competitions.

- Application Interface: The application's main page, including all components of the application as described in the following figure No (2): 


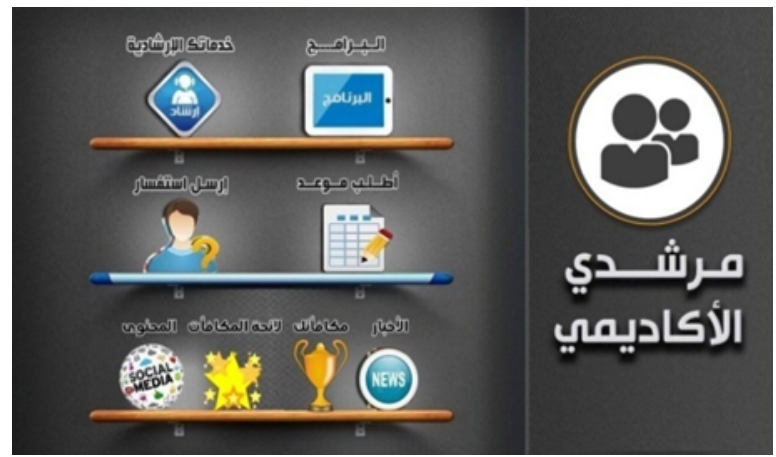

Fig. 2. Main interface of application

Educational content organization: Content is presented constructively so that the learner will be able to access the main ideas of the content through channels of social communication identified in channels (4), which were mentioned previously, and linked to the developed application.

Educational strategies design: Several strategies have been adopted, including: competitive learning, collaborative learning, participatory learning, research learning, problem solving, and project-based learning, in a manner such strategies can suit the gamification system.

Development stage: At this stage, the overall structure of the application was produced by android studio, and the three components of the application were developed, which included guidance and counseling tools, content tools and gamification tools, as well as the production of some digital media that would be used in the digital content application.

Implementation stage: Under digital content application, prior application of gamification well-being scale was implemented, then launching the process of learning and implementation of tasks through application, Implementation of the learning strategies identified during the implementation of the educational tasks, then considering the post-application of PWB through MDCA.

\section{$4 \quad$ Results}

\subsection{The scale of PWB through (MDCA):}

The PWB scale, as presented in the theoretical framework, and the procedures carried out in the preparation of the search tool, included (6) various themes: autonomy, environmental enabling, personal development, positive relationships, purposeful life, Self-acceptance, and the scale composes of (36) vocabularies, were distributed on the six themes, 6 vocabularies for each theme. 


\subsection{The proposed model for (MDCA) Based on gamification:}

The mobile digital content application gamifications suggested model is reached as discussed in the research procedures. The Model (3) included basic components for MDCA, model (10) covers characteristics of gamification using the mobile digital content application, (7) characteristics of mobile applications in general, (10) diverse mechanisms, (5) dynamic elements of gamification, (4) theories forming the basic principles of the gamification system, (3) gamification tools, (3) principles for managing incentives, and Figure (3) below illustrates the components of the proposed model and Details.

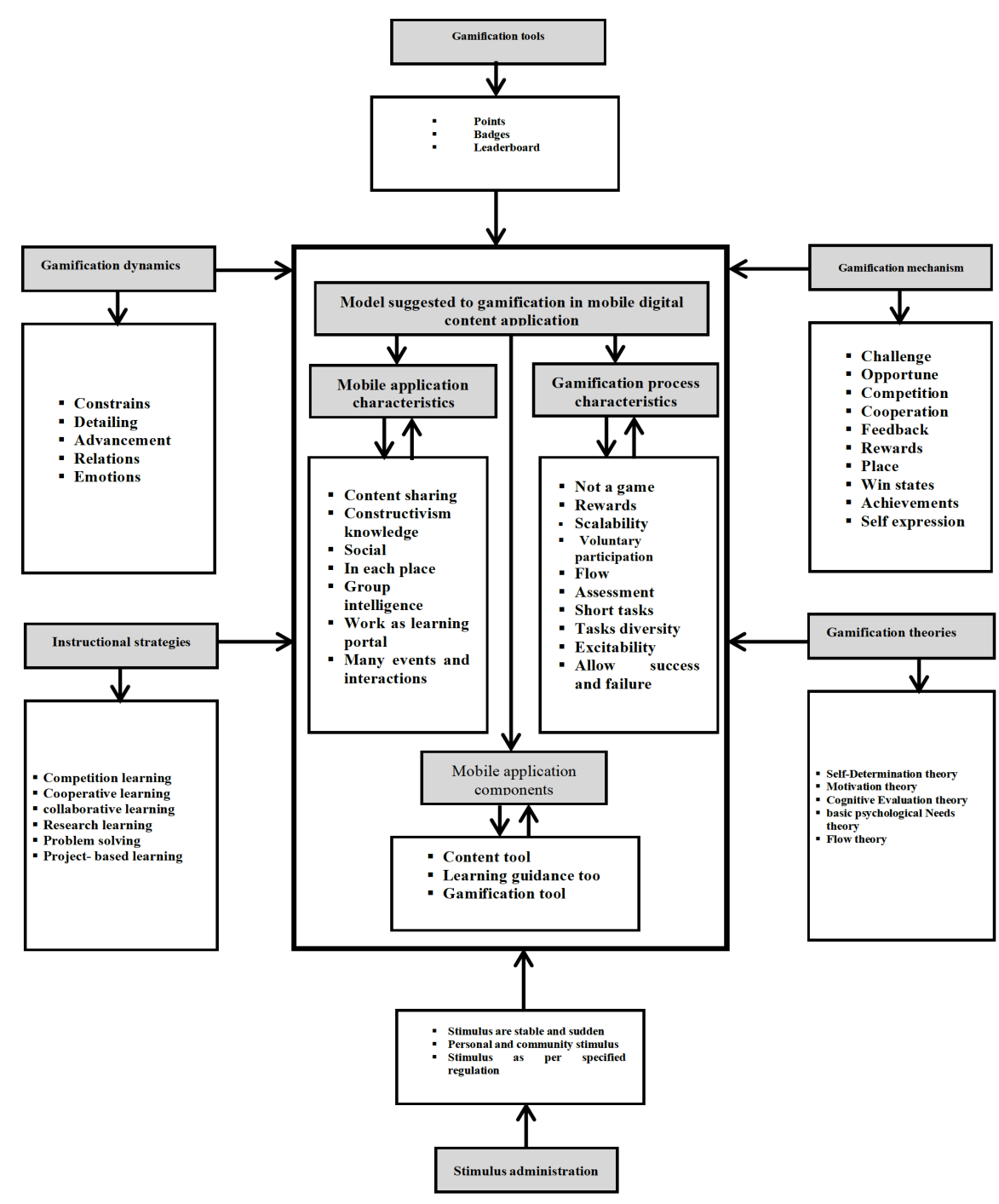

Fig. 3. The proposed model for (MDCA) Based on gamification 


\subsection{The effectiveness of (MDCA) based on gamification in the development of (PWB)}

T-test was used to recognize the significance of difference between the experimental group (1) and experimental group (2), to verify the validity of the first hypothesis of the comparison between the first group that used the application of the developed digital content without relying on the gamification system and the second group that used the proposed model for MDCA based on the gamification system.

Table (3) shows the results of the $\mathrm{T}$ test for the research both groups individual degree averages

Table 3. The arithmetic mean, standard deviation, and t-test with regard to the research both groups individuals degree average

\begin{tabular}{|l|c|c|c|c|c|c|}
\hline \multicolumn{1}{|c|}{ Group } & N & Mean & SD & t & DF & Sig \\
\hline $\begin{array}{l}\text { Group (1) MDCA without gamification } \\
\text { system }\end{array}$ & 31 & 125.71 & 2.39 & & & \\
$\begin{array}{l}\text { Group (2) The suggested MDCA based on the } \\
\text { gamification system }\end{array}$ & 31 & 169.62 & 3.81 & 44.70 & 60 & 0.000 \\
\hline
\end{tabular}

There are statistically significant differences, as shown in the previous table, between the experimental group (2) using the proposed application based on the gamification $(\mathrm{M}=169.62, \mathrm{SD}=3.81)$ and the first group that used the application without the gamification system $(\mathrm{M}=125.71, \mathrm{SD}=2.39)(\mathrm{t}=44.70),(\mathrm{p}=.000)$. Therefore, the hypothesis can be modified to mean that "there are statistically significant differences in the mean score of 0.05 between the mean scores of the experimental group (1) students (using a mobile application based on the methods of gamification) and the mean of the first group (using a mobile application without any methods of gamification).

\section{Discussion}

The above-mentioned result, which has led to the effectiveness model proposed for gamification and the role of which in the development of PWB through applications of digital mobile content in comparison with MDCA that do not rely on methods of gamification, is based on the fact that the gamification system has contributed to create the highest motivation among the learners of the sample. This great motivation has contributed in placing the learners in an active and motivated mood, this led them to exercise all their tasks independently and control the digital mobile environment, as well as the desire to overcome the educational challenges facing them to improve the personal growth of their learning-related skills, and to successfully complete the learning tasks. The experimental group was able to build positive relationships among learning groups individuals. Such positive relationships are reflected on the learners' ability to build level goals and an ability to achieve success in each of these levels, which makes them feel self-satisfied. All previous factors were reflected on the total 
indicator of the PWB of the experimental group, which was higher than that of the students of the traditional group [34, 45-47].

Gamification incentives also contributed to a rising state of well-being that led learners to complete their learning tasks. Each incentive represents the beginning of a new rise in the well-being indicator. According to Skinner theory of reinforcement, rewards greatly stimulate the continuation of positive practices, and guarantee that these practices do not fade with time [45]. According to the flow theory, providing positive incentives at varying intervals of time is relevant to the human nature which is largely based on internal motivations stimulated by external obtained reward [43] This corresponds to the study of [7], which suggests that Reward-based Intermittent Reinforcement is one of the most reliable types of gamification systems, as it emphasizes the learner's autonomy and does not affect the learner's internal motivations. In addition, they provide the learner with a state of joy and fun. The flexible adaptive tasks that have been used have supported the learner's personal flexibility in carrying out tasks, moving between the graduating levels of a challenge, and stimulating the building of positive relationships to maintain continuity of the flow state. This supports the processes of environmental empowerment and learner's personal development and the practice of all activities and tasks under clear and specific goals, which eventually led to a rise in the indicators of learner's PWB [37] [38]. The current study results are consistent with a large number of studies that have indicated the effectiveness of gamification in the development of various learning outcomes such as [48], which demonstrated the effectiveness of learning to increase student productivity. And a study by [49], showed that digital badges are effective in increasing the amount of learners' participation,[47], showed the effectiveness of gamification in developing cognitive achievement, [50] demonstrated the effectiveness of gamification in developing motivation for achievement. [51], demonstrated the effectiveness of gamification in reducing the dispersion of learners.

\section{Conclusion}

The current research is one of the researches that focused on the design elements to develop gamification systems through digital content applications, through which gamification systems can be applied. The research aims at determining the relationship between the applications of digital content based on the gamification and the PWB of postgraduate students through these applications. The best applications depending on gamification on the PWB compared to applications without methods of gamification have specified. In the opinion of the research team that future research related to the employment of gamification through e-learning environments may be more oriented towards study of the intensity of elements of games that can be used within the relevant environment, in addition to finding a clear relationship between the components of visual and verbal games. Nevertheless, study of gamification through electronic learning is of high importance. The research team, also, believes that it is necessary to have a new research trend that aims at establishing a clear framework for the digital environment- gamification for people with special needs 
such as deaf or blind. Also, linking the gamification to the augmented reality is one of the research issues to be studied.

\section{$7 \quad$ References}

[1] P. Buckley and E. Doyle, "Individualising gamification: An investigation of the impact of learning styles and personality traits on the efficacy of gamification using a prediction market," Computers \& Education, vol. 106, pp. 43-55, 2017/03/01/ 2017. https://doi.org/ 10.1016/j.compedu.2016.11.009

[2] S. Deterding, M. Sicart, L. Nacke, K. O'Hara, and D. Dixon, "Gamification. using gamedesign elements in non-gaming contexts," in CHI'11 extended abstracts on human factors in computing systems, 2011, pp. 2425-2428. https://doi.org/10.1145/1979742.1979575

[3] S. Nebel, S. Schneider, M. Beege, and G. D. Rey, "Leaderboards within educational videogames: The impact of difficulty, effort and gameplay," Computers \& Education, vol. 113, pp. 28-41, 2017/10/01/2017. https://doi.org/10.1016/j.compedu.2017.05.011

[4] C. Perryer, N. A. Celestine, B. Scott-Ladd, and C. Leighton, "Enhancing workplace motivation through gamification: Transferrable lessons from pedagogy," The International Journal of Management Education, vol. 14, pp. 327-335, 2016. https://doi.org/10.1016/ j.ijme.2016.07.001

[5] E. L. Deci, R. Koestner, and R. M. Ryan, "Extrinsic rewards and intrinsic motivation in education: Reconsidered once again," Review of educational research, vol. 71, pp. 1-27, 2001. https://doi.org/10.3102/00346543071001001

[6] E. Kyewski and N. C. Krämer, "To gamify or not to gamify? An experimental field study of the influence of badges on motivation, activity, and performance in an online learning course," Computers \& Education, vol. 118, pp. 25-37, 2018/03/01/ 2018. https://doi.org/ 10.1016/j.compedu.2017.11.006

[7] S. Luo, H. Yang, and C. Meinel, "Reward-based Intermittent Reinforcement in Gamification for E-learning," in CSEDU (1), 2015, pp. 177-184. https://doi.org/10.5220/000540220 1770184

[8] S. L. Wise and C. E. DeMars, "Low Examinee Effort in Low-Stakes Assessment: Problems and Potential Solutions," Educational Assessment, vol. 10, pp. 1-17, 2005/02/01 2005. https://doi.org/10.1207/s15326977ea1001 1

[9] C. McLoughlin and M. J. Lee, "Personalised and self regulated learning in the Web 2.0 era: International exemplars of innovative pedagogy using social software," Australasian Journal of Educational Technology, vol. 26, 2010. https://doi.org/10.14742/ajet.1100

[10] C. Hu, C. Zhang, T. Wang, and Q. Li, "An adaptive recommendation system in social media," in System Science (HICSS), 2012 45th Hawaii International Conference on, 2012, pp. 1759-1767. https://doi.org/10.1109/hicss.2012.94

[11] W. S. Al-halafawy and M. Z. Tawfiq, "The Relationship between Types of Image Retrieval and Cognitive Style in Developing Visual Thinking Skills," Life Science Journal, vol. 11, pp. 865-879, 2014.

[12] H.-T. Chen and X. Li, "The contribution of mobile social media to social capital and psychological well-being: Examining the role of communicative use, friending and selfdisclosure," Computers in Human Behavior, vol. 75, pp. 958-965, 2017/10/01/ 2017. https://doi.org/10.1016/j.chb.2017.06.011

[13] S. Y. Park and Y. M. Baek, "Two faces of social comparison on Facebook: The interplay between social comparison orientation, emotions, and psychological well-being," Comput- 
ers in Human Behavior, vol. 79, pp. 83-93, 2018/02/01/ 2018. https://doi.org/10.1016/ j.chb.2017.10.028

[14] P. Barr, "Video game values: Play as human-computer interaction," Doctoral Dissertation, Victoria University of Wellington, 2008.

[15] S. Deterding, D. Dixon, R. Khaled, and L. Nacke, "From game design elements to gamefulness: defining gamification," in Proceedings of the 15th international academic MindTrek conference: Envisioning future media environments, 2011, pp. 9-15. https://doi.org /10.1145/2181037.2181040

[16] K. K. Hewitt, W. Journell, and R. Zilonka, "What the flip: impact of flipped instruction on self-regulated learning," International Journal of Social Media and Interactive Learning Environments, vol. 2, pp. 303-325, 2014. https://doi.org/10.1504/ijsmile.2014.067638

[17] M. Sailer, J. Hense, H. Mandl, and M. Klevers, "Psychological Perspectives on Motivation through Gamification," IxD\&A, vol. 19, pp. 28-37, 2013.

[18] P. Andersen, What is Web 2.0?: ideas, technologies and implications for education vol. 1: JISC Bristol, 2007.

[19] G. Solomon and L. Schrum, Web 2.0: New tools, new schools: ISTE (Interntl Soc Tech Educ, 2007.

[20] K. Salmi, H. Magre, H. Sefraoui, and A. Ziyyat, "Development of a Mobile Application for Teaching Transmission Line Theory," International Journal of Interactive Mobile Technologies (iJIM), vol. 13, pp. 78-88, 2018. https://doi.org/10.3991/ijim.v13i02.10000

[21] A. A. Zeidan, W. S. Alhalafawy, M. Z. Tawfiq, and W. R. Abdelhameed, "The effectiveness of some e-blogging patterns on developing the informational awareness for the educational technology innovations and the King Abdul-Aziz University postgraduate students' attitudes towards it," Life Science Journal, vol. 12, 2015.

[22] I. Chard, "Share, Collaborate, Exploit Defining Mobile Web 2.0," Juniper Research. Hampshire, England, 2008.

[23] S. Wijaya, M. R. Spruit, and W. J. Scheper, "Webstrategy formulation: Benefiting from web 2.0 concepts to deliver business values," in Web 2.0, ed: Springer, 2009, pp. 1-30. https://doi.org/10.1007/978-0-387-85895-1 7

[24] N. Mills, "Situated learning through social networking communities: The development of joint enterprise, mutual engagement, and a shared repertoire," Calico Journal, vol. 28, pp. 345-368, 2011. https://doi.org/10.11139/cj.28.2.345-368

[25] F. Ozdamli and E. Ercag, "Opinions of Teacher Candidates on the Usage of Mobile Applications in the Multimedia Development Processes," International Journal of Interactive Mobile Technologies (iJIM), vol. 12, pp. 27-38, 2018. https://doi.org/10.3991/ijim.v1 $\underline{2 \mathrm{i} 2.7679}$

[26] H. H. Muljo, A. S. Perbangsa, and B. P. Yulius, "Mobile Learning for Early Detection Cancer," International Journal of Interactive Mobile Technologies (iJIM), vol. 12, pp. 3953, 2018. https://doi.org/10.3991/ijim.v12i2.7814

[27] Z. Karabatzaki, A. Stathopoulou, G. Kokkalia, E. Dimitriou, P. I. Loukeri, A. Economou, et al., "Mobile Application Tools for Students in Secondary. https://doi.org/10.3991/ijim.v $\underline{12 \mathrm{i} 2.8158}$

[28] Education. An Evaluation Study," International Journal of Interactive Mobile Technologies (iJIM), vol. 12, pp. 142-161, 2018.

[29] H. Hedberg, J. Nouri, P. Hansen, and R. Rahmani, "A Systematic Review of Learning through Mobile

[30] Augmented Reality," International Journal of Interactive Mobile Technologies (iJIM), vol. 12, pp. 75-85, 2018. 
[31] N. Aljojo, "The Design and Implementation of a Mathematics GameBase Learning Application for Primary Students," International Journal of Interactive Mobile Technologies (iJIM), vol. 12, pp. 142-152, 2018. https://doi.org/10.3991/ijim.v12i3.8739

[32] M. A. Al-Khateeb, "The Effect of Teaching Mathematical Problems Solving Through Using Mobile Learning on the Seventh Grade Students' Ability to Solve them in Jordan," International Journal of Interactive Mobile Technologies (iJIM), vol. 12, pp. 78-191, 2018. https://doi.org/10.3991/ijim.v12i3.8713

[33] A. A. Zeidan, W. S. Alhalafawy, and M. Z. Tawfiq, "The Effect of (Macro/Micro) Wiki Content Organization on Developing Metacognition Skills," Life Science Journal, vol. 14, p. 12, 2017.

[34] C. Ryff, "Psychological Well-being in Adult Life, Current Directions," Psychological Science, vol. 4, pp. 99-104, 1995. https://doi.org/10.1111/1467-8721.ep10772395

[35] C. D. Ryff, "Happiness is everything, or is it? Explorations on the meaning of psychological well-being," Journal of personality and social psychology, vol. 57, p. 1069, 1989. https://doi.org/10.1037//0022-3514.57.6.1069

[36] C. D. Ryff and B. H. Singer, "Know thyself and become what you are: A eudaimonic approach to psychological well-being," in The exploration of happiness, ed: Springer, 2008, pp. 97-116. https://doi.org/10.1007/978-94-007-5702-8_6

[37] K. W. Springer and R. M. Hauser, "An assessment of the construct validity of Ryff's scales of psychological well-being: Method, mode, and measurement effects," Social science research, vol. 35, pp. 1080-1102, 2006. https://doi.org/10.1016/j.ssresearch.2005.07.0 $\underline{04}$

[38] R. M. Ryan and E. L. Deci, "Self-determination theory and the facilitation of intrinsic motivation, social development, and well-being," American psychologist, vol. 55, p. 68, 2000. https://doi.org/10.1037//0003-066x.55.1.68

[39] M. Sailer, J. U. Hense, S. K. Mayr, and H. Mandl, "How gamification motivates: An experimental study of the effects of specific game design elements on psychological need satisfaction," Computers in Human Behavior, vol. 69, pp. 371-380, 2017/04/01/ 2017. https://doi.org/10.1016/j.chb.2016.12.033

[40] A. Suh, C. Wagner, and L. Liu, "The effects of game dynamics on user engagement in gamified systems," in System Sciences (HICSS), 2015 48th Hawaii International Conference on, 2015, pp. 672-681. https://doi.org/10.1109/hicss.2015.87

[41] R. M. Ryan and E. L. Deci, "Intrinsic and Extrinsic Motivations: Classic Definitions and New Directions," Contemporary Educational Psychology, vol. 25, pp. 54-67, 2000/01/01/ 2000. https://doi.org/10.1006/ceps.1999.1020

[42] K. Seaborn and D. I. Fels, "Gamification in theory and action: A survey," International Journal of Human-Computer Studies, vol. 74, pp. 14-31, 2015/02/01/ 2015. https://doi.org/ 10.1016/j.ijhcs.2014.09.006

[43] J. Simões, R. D. Redondo, and A. F. Vilas, "A social gamification framework for a K-6 learning platform," Computers in Human Behavior, vol. 29, pp. 345-353, 2013. https://doi.org/10.1016/i.chb.2012.06.007

[44] G. Zichermann and C. Cunningham, Gamification by design: Implementing game mechanics in web and mobile apps: " O'Reilly Media, Inc.", 2011.

[45] F. Groh, "Gamification: State of the art definition and utilization," Institute of Media Informatics Ulm University, vol. 39, 2012.

[46] J. Nakamura and M. Csikszentmihalyi, "Flow theory and research," Handbook of positive psychology, pp. 195-206, 2009. 
[47] G. Richter, D. R. Raban, and S. Rafaeli, "Studying gamification: the effect of rewards and incentives on motivation," in Gamification in education and business, ed: Springer, 2015, pp. 21-46. https://doi.org/10.1007/978-3-319-10208-5 2

[48] S.-K. Thiel, "Reward-based vs. Social Gamification: Exploring Effectiveness of Gamefulness in Public Participation," in Proceedings of the 9th Nordic Conference on HumanComputer Interaction, 2016, p. 104. https://doi.org/10.1145/2971485.2996739

[49] Z. Turan, Z. Avinc, K. Kara, and Y. Goktas, "Gamification and Education: Achievements, Cognitive Loads, and Views of Students," International journal of emerging technologies in learning, vol. 11, 2016. https://doi.org/10.3991/ijet.v11i07.5455

[50] M. Restivo and A. Van De Rijt, "Experimental study of informal rewards in peer production," PloS one, vol. 7, p. e34358, 2012. https://doi.org/10.1371/journal.pone.0034358

[51] P. Denny, "The effect of virtual achievements on student engagement," in Proceedings of the SIGCHI conference on human factors in computing systems, 2013, pp. 763-772. https://doi.org/10.1145/2470654.2470763

[52] K. F. Hew, B. Huang, K. W. S. Chu, and D. K. Chiu, "Engaging Asian students through game mechanics: Findings from two experiment studies," Computers \& Education, vol. 92, pp. 221-236, 2016. https://doi.org/10.1016/i.compedu.2015.10.010

[53] D. Kayımbaşığlu, B. Oktekin, and H. Hacı, "Integration of Gamification Technology in Education," Procedia Computer Science, vol. 102, pp. 668-676, 2016. https://doi.org/10.10 16/j.procs.2016.09.460

\section{Authors}

Dr. Waleed Salim Mohamed Alhalafawy, Professor, Instructional technology Department, College of Educational Graduate Studies, king abdulaziz University, Jeddah- Saudi Arabia, and Ain shams university, Cairo, Egypt, Research Interests in the field of e-learning, digital video, applications of smart phones, digital platforms. (e-mail: welhlafawy@kau.edu.sa,waleed_doc@hotmail.com)

Dr. Marwa Zaki Tawfiq Zaki, associate Professor, Instructional technology Department, College of Specific Education, Ain Shams University, Cairo, Egypt, Research Interests in the field of E-Learning, Mobile Games, 3D environments, Augmented Reality. (e-mail: dr.marwa.zaki@sedu.asu.edu.eg,drmarwaa_doc@hotmail. com)

Article submitted 2019-04-23. Resubmitted 2019-05-25. Final acceptance 2019-05-26. Final version published as submitted by the authors. 